\title{
Pseudoxanthoma Elasticum as a Paradigm of Heritable Ectopic Mineralization Disorders
}

\section{Pathomechanisms and Treatment Development}

\author{
Qiaoli Li, Koen van de Wetering, and Jouni Uitto
}

From the Department of Dermatology and Cutaneous Biology, Sidney Kimmel Medical College, the PXE International Center of Excellence in Research and Clinical Care, and the Jefferson Institute of Molecular Medicine, Thomas Jefferson University, Philadelphia, Pennsylvania

Accepted for publication September 26, 2018.

Address correspondence to Qiaoli Li, Ph.D., Department of Dermatology and Cutaneous Biology, Sidney Kimmel Medical College, Thomas Jefferson University, 233 S 10th St., Ste. 431 BLSB, Philadelphia, PA 19107. E-mail: qiaoli.li@ jefferson.edu.

\begin{abstract}
Ectopic mineralization is a global problem and leading cause of morbidity and mortality. The pathomechanisms of ectopic mineralization are poorly understood. Recent studies on heritable ectopic mineralization disorders with defined gene defects have been helpful in elucidation of the mechanisms of ectopic mineralization in general. The prototype of such disorders is pseudoxanthoma elasticum (PXE), a late-onset, slowly progressing disorder with multisystem clinical manifestations. Other conditions include generalized arterial calcification of infancy (GACI), characterized by severe, early-onset mineralization of the cardiovascular system, often with early postnatal demise. In addition, arterial calcification due to CD73 deficiency (ACDC) occurs late in life, mostly affecting arteries in the lower extremities in elderly individuals. These three conditions, PXE, GACI, and ACDC, caused by mutations in $A B C C 6, E N P P 1$, and NT5E, respectively, are characterized by reduced levels of inorganic pyrophosphate (PPi) in plasma. Because PPi is a powerful antimineralization factor, it has been postulated that reduced $\mathrm{PPi}$ is a major determinant for ectopic mineralization in these conditions. These and related observations on complementary mechanisms of ectopic mineralization have resulted in development of potential treatment modalities for PXE, including administration of bisphosphonates, stable PPi analogs with antimineralization activity. It is conceivable that efficient treatments may soon become available for heritable ectopic mineralization disorders with application to common calcification disorders. (Am J Pathol 2019, 189: 216-225; https://doi.org/10.1016/j.ajpath.2018.09.014)
\end{abstract}

\section{Ectopic Mineralization: A Global Problem}

Ectopic mineralization (ie, deposition of calcium/phosphate complexes on connective tissues in aberrant locations) is a subject that has attracted much attention because of it being a leading cause of morbidity and mortality. Of special interest is its wide association with several acquired clinical conditions, such as aging, cancer, diabetes, and autoimmune diseases. ${ }^{1,2}$ There are two forms of ectopic mineralization (ie, dystrophic and metastatic calcification). Dystrophic calcification occurs in pathologically altered tissues with normal serum levels of calcium and phosphate, whereas metastatic calcification occurs in normal tissues associated with increased serum levels of calcium and phosphate. The pathomechanistic details of ectopic mineralization are poorly understood. However, recent studies on Mendelian ectopic mineralization disorders caused by mutations in distinct genes, with defined pathomechanistic consequences, have been extremely helpful toward elucidation of the mechanisms of ectopic mineralization processes in general.

Supported by the NIH/National Institute of Arthritis and Musculoskeletal and Skin Diseases grants K01AR64766 (Q.L.), R01AR28450 (J.U.), R01AR55225 (J.U., Q.L.), and R01AR72695 (Q.L., J.U., K.v.d.W.); and PXE International (K.v.d.W.).

Disclosures: None declared. 


\section{Pseudoxanthoma Elasticum: The Prototype of Heritable Ectopic Mineralization Disorders}

The prototype of heritable ectopic mineralization diseases with normal calcium and phosphate homeostasis is pseudoxanthoma elasticum (PXE), an autosomal recessive disorder characterized by protean manifestations in the skin, arterial blood vessels, and the eyes (Figure 1). ${ }^{4}$ A diagnostic histopathologic feature in PXE is accumulation of fragmented pleiomorphic elastotic structures in the skin, which become progressively mineralized. These observations initially suggested that the mutations in PXE may reside in genes encoding elastin or elastin-associated microfibrils. However, early genetic linkage studies largely excluded these genes as the site of causative mutations in this disorder. ${ }^{5,6}$

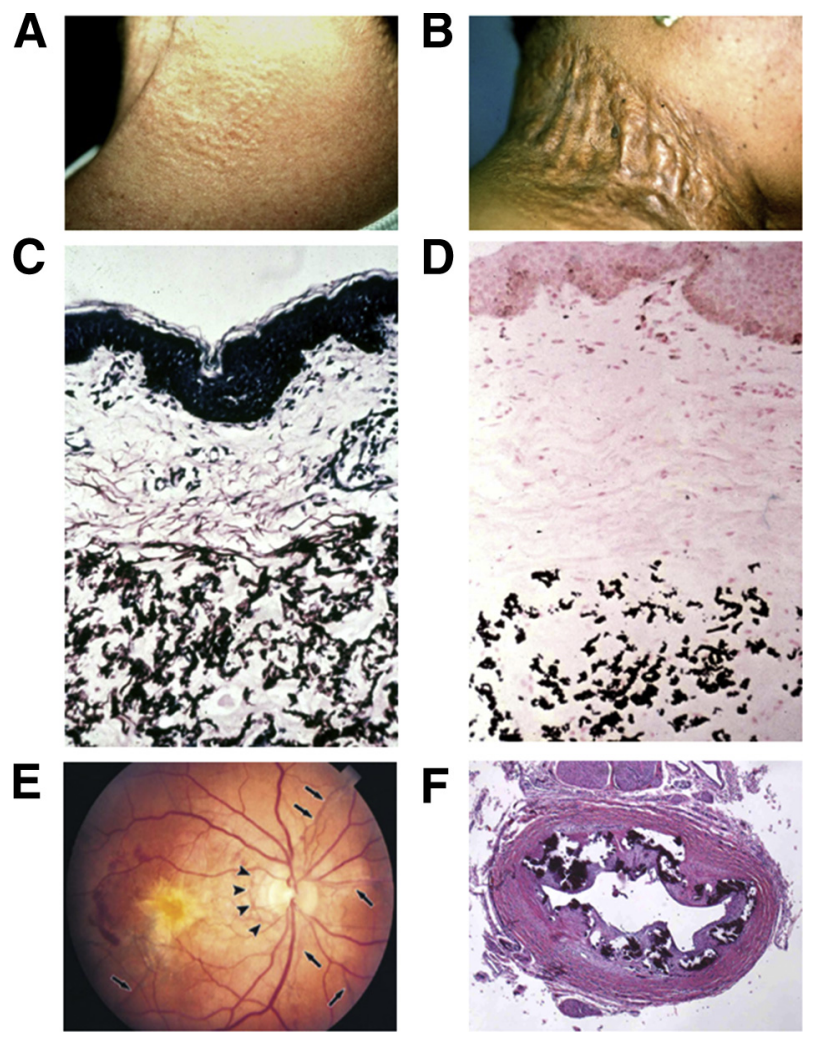

Figure 1 Clinical features and histopathology of ectopic mineralization in pseudoxanthoma elasticum (PXE). A: Characteristic early cutaneous signs of PXE consist of discrete yellowish papules at predilection sites, such as sides of the neck. B: These early lesions coalesce into plaques of inelastic, leathery skin. C: Histopathology of the affected area of skin reveals accumulation of pleiomorphic elastotic material in the mid dermis, as visualized by Verhoeff-van Gieson stain. D: Staining of a parallel section with von Kossa stain reveals mineralization of the elastotic structures. E: Characteristic ocular findings consist of angioid streaks, breaks in the Bruch membrane behind the retina (arrows), which allow neovascularization (arrowheads) of the retina, leading to loss of visual acuity and blindness. F: Histopathology of the left renal artery in a generalized arterial calcification of infancy patient with $A B C C 6$ mutations reveals extensive mineralization (hematoxylin-eosin stain). Adapted with permission from Uitto et al.
PXE is caused in most cases by mutations in the $A B C C 6$ gene that encodes ABCC6 (ATP-binding cassette, subfamily $\mathrm{C}$, member 6), a transmembrane efflux transporter. The substrate(s) of ABCC6 remain unknown; however, the tissue-specific expression pattern of ABCC6 has been extensively studied. An initially puzzling observation was that liver is the primary site of ABCC6 expression distal from the tissues directly affected by mineralization in PXE. This paradox, together with studies using knockout mouse and rat models as a platform, was resolved by suggestions that PXE is a metabolic disorder with the primary molecular defect residing in the liver. ${ }^{8,9}$

The estimated prevalence of PXE is approximately 1:50,000, which implies that there are approximately 7000 affected individuals in the United States. If extrapolated to the global population, the number of patients experiencing PXE increases to approximately 150,000 worldwide. More than 300 distinct loss-of-function mutations have been encountered in the ABCC6 gene, including recurrent p.R1141X and g.del23-29, which account for up to approximately $45 \%$ of all mutations. ${ }^{10}$

\section{The Spectrum of Ectopic Mineralization Disorders}

There are several heritable ectopic mineralization disorders with overlapping phenotypic features. ${ }^{2,11}$ Compared with PXE, patients with generalized arterial calcification of infancy (GACI) develop severe and early-onset mineralization of the cardiovascular system. Most children die from cardiovascular collapse within the first 6 months of life if left untreated. ${ }^{12}$ Arterial calcification due to deficiency of CD73 (ACDC) is a rare, adult-onset ectopic mineralization disorder affecting the arteries of the lower extremities and periarticular ligaments. ${ }^{13,14}$ Mutations in the ABCC6, ENPPI, and NT5E genes underlie ectopic mineralization for the classic forms of PXE, GACI, and ACDC, respectively (Figure 2). Although these three conditions are distinct diagnostic entities with a different natural history, there are similarities in clinical presentations, particularly the vascular involvement. Some patients with $A B C C 6$ mutations have manifestations similar to GACI, and some patients with ENPP1 mutations present with features of PXE. ${ }^{11,15}$ These observations have led to the hypothesis that PXE and GACI represent the two ends of a clinical spectrum but share alterations in the same pathways. In fact, recent studies by us, and confirmed by others, have indicated a unifying pathomechanistic feature in PXE, GACI, and ACDC involving reduction of the circulating antimineralization factor, inorganic pyrophosphate (PPi) (Figure 2).

In addition to the diseases involving reduced PPi in the pathomechanisms of ectopic mineralization, several heritable conditions with distinct gene defects, and presumably different pathomechanisms, have been characterized. One of such conditions is the PXE-like phenotype with multiple coagulation factor deficiency. These patients manifest with cutaneous 


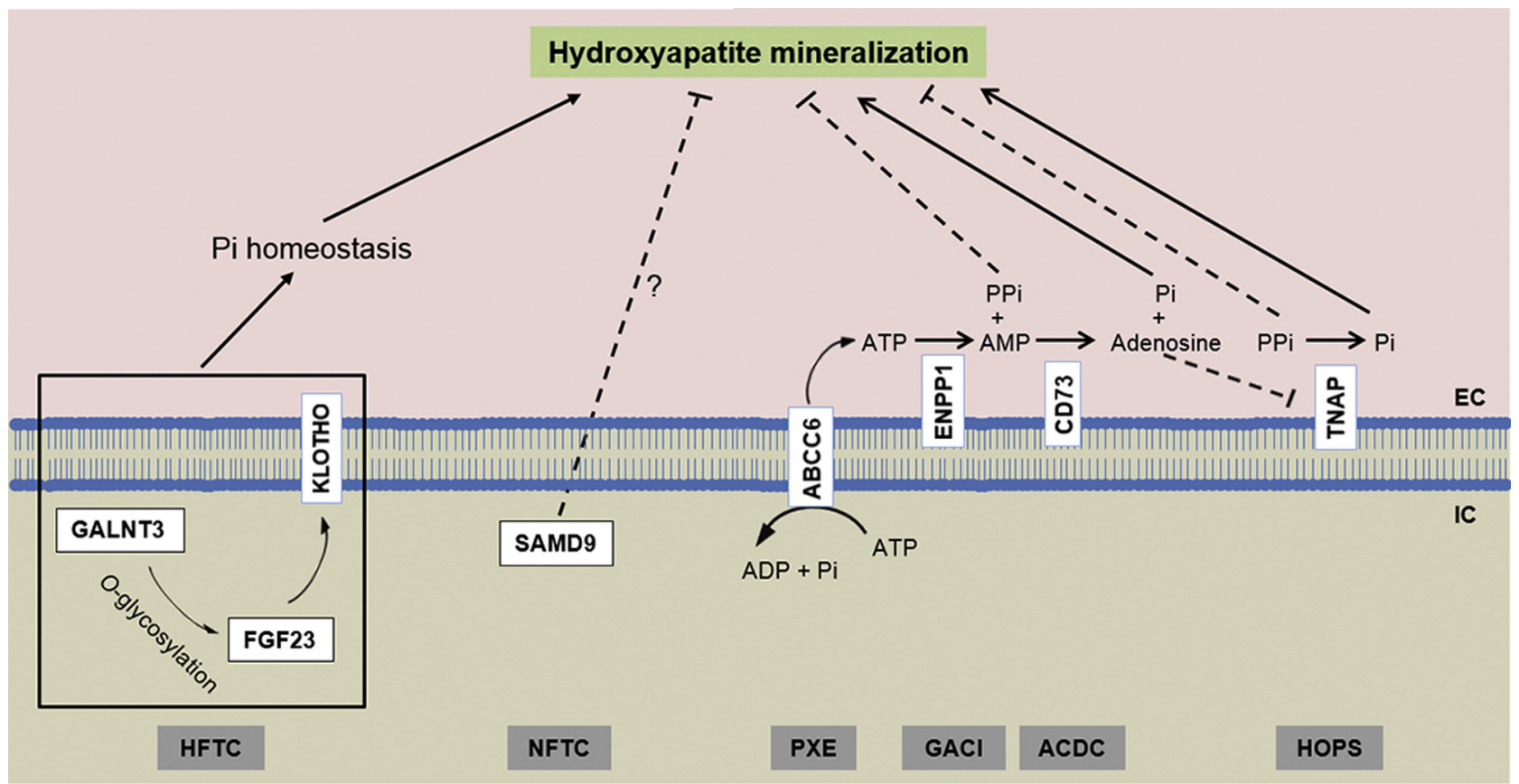

Figure 2 Different pathomechanisms controlling ectopic mineralization. Hyperphosphatemic familial tumoral calcinosis (HFTC) is associated with altered $\mathrm{Pi}$ homeostasis (marked hyperphosphatemia) because of mutations in one of the three proteins involved in the regulation of inorganic phosphate ( $\mathrm{Pi}$ ) excretion in the kidney (GALNT3, FGF23, and KLOTH0). Normophosphatemic familial tumoral calcinosis (NFTC) is caused by mutations in the SAMD9 gene with unknown function in prevention of ectopic mineralization without altered serum phosphate levels. ATP-binding cassette, subfamily C, member 6 (ABCC 6 ), ectonucleotide pyrophosphotase/phosphodiesterase 1 (ENPP1), and $5^{\prime}$-ecto nucleotidase (CD73) are plasma membrane-associated proteins controlling the synthesis and degradation of inorganic pyrophosphate (PPi). ENPP1 is the principal enzyme that generates PPi from ATP hydrolysis. ABCC6 works upstream of ENPP1 by mediating release of ATP, a substrate for ENPP1. CD73 cleaves AMP to adenosine and Pi, with adenosine being an inhibitor of tissue nonspecific alkaline phosphatase (TNAP), which degrades PPi. Mutations in these proteins result in pseudoxanthoma elasticum (PXE), generalized arterial calcification of infancy (GACI), and arterial calcification due to deficiency of CD73 (ACDC), respectively, all characterized by reduced plasma PPi levels. Loss-of-function mutations in the gene encoding TNAP, which degrades PPi to Pi, result in hypophosphatasia (HOPS) attributable to increased plasma PPi levels. Adapted with permission from Uitto et al. $^{3} \mathrm{EC}$, extracellular; IC, intracellular.

findings reminiscent of PXE with ultrastructurally demonstrable depositions of calcium complexes in the dermis. However, the skin findings also include severe skin laxity with thick and leathery skin folds, findings reminiscent of cutis laxa. Thus, these patients demonstrate overlapping cutaneous features of PXE and cutis laxa. ${ }^{16}$ The patients also demonstrate deficiency in vitamin $\mathrm{K}$-dependent coagulation factors (II, VII, IX, and X). No mutations were found in the ABCC6 or VKORCl genes in these patients. ${ }^{16,17}$ Instead, mutations have been disclosed in $G G C X$, a gene encoding $\gamma$-glutamyl carboxylase, together with reduced carboxylation of matrix gla protein. Thus, reduced matrix gla protein carboxylation allows mechanistically tissue mineralization in the skin to occur with phenotypic consequences. These studies established GGCX as the second gene locus causing PXE and provided additional mechanistic details for ectopic mineralization. ${ }^{16,17}$ Interestingly, in one family with PXE-like cutaneous features, some individuals were heterozygous for a missense mutation p.V255M in $G G C X$ and heterozygous for a null mutation p.R1141X in $A B C C 6$, suggesting the digenic nature of their skin findings and implying a role for multiple genetic factors in pathologic tissue mineralization in general. ${ }^{18}$ Another ectopic mineralization disorder, familial tumoral calcinosis, exists in two broad forms (ie, hyperphosphatemic due to altered $\mathrm{Pi}$ homeostasis and normophosphatemic with normal serum $\mathrm{Pi}$ levels) (Figure 2). Hyperphosphatemic familial tumoral calcinosis is characterized by ectopic mineralization and hyperphosphatemia due to disturbed renal Pi reabsorption. The disease is caused by mutations in any one of three genes, $G A L N T 3, K L$, and $F G F 23$, resulting in progressive mineralization in periarticular spaces and soft tissues. ${ }^{19}$ Normophosphatemic familial tumoral calcinosis manifests with extensive ectopic mineralization of the cutaneous tissues, associated with inflammatory manifestations preceding mineralization. Normophosphatemic familial tumoral calcinosis is caused by lossof-function mutations in the $S A M D 9$ gene with no currently known function. $^{20,21}$

\section{Development of Animal Models to Study Ectopic Mineralization Disorders}

The $A b c c 6^{-/-}$mouse was developed as a model for PXE in $2005{ }^{22,23}$ Subsequently, several naturally occurring $A b c c 6$ mutant mice have been characterized. ${ }^{24-26}$ The focus has been on phenotypic characterization of four mouse strains, $\mathrm{KK} / \mathrm{HIJ}, \mathrm{C} 3 \mathrm{H} / \mathrm{HeJ}, \mathrm{DBA} / 2 \mathrm{~J}$, and 129S1/SvImJ, that harbor the same single-nucleotide polymorphism (rs32756904) in 
the Abcc6 gene interfering with pre-mRNA splicing and resulting in frameshift of translation, but histopathology demonstrates highly variable mineralization phenotypes affecting several connective tissues. Attesting to the effect of the genetic background on the phenotype are observations that the $\mathrm{KK} / \mathrm{HIJ}$ strain displays the most severe mineralization phenotype, whereas $\mathrm{C} 3 \mathrm{H} / \mathrm{HeJ}$ and $\mathrm{DBA} / 2 \mathrm{~J}$ strains with the same Abcc6 mutation demonstrate extremely mild mineralization. The acceleration of ectopic mineralization in these mice by an experimental diet, enriched in phosphate and low in magnesium, reinforces the role of dietary factors in modulation of the ectopic mineralization phenotype. ${ }^{26}$ Collectively, these mice have served as novel spontaneous models for PXE, and they have been used as a platform for examining the pathophysiology as well as for identification of genetic factors that modify the PXE phenotype.

Two mutant mouse strains, Enppl $1^{a s j}$ and Enppl ${ }^{a s j-2 J}$, have also been characterized as novel models for GACI. ${ }^{27,28}$ The asj allele was shown to harbor a homozygous missense mutation, p.V246D, in the Enppl gene, resulting in marked reduction in the corresponding protein in the liver, associated with extensive mineralization of the skin and arterial blood vessels. Genetic characterization of the $a s j-2 J$ allele revealed an insertion/deletion mutation in the Enppl gene, leading to complete loss of ENPP1 enzymatic activity and, consequently, the plasma PPi concentration was essentially undetectable, resulting in extensive ectopic mineralization of the arterial blood vessels. Thus, Enppl $1^{a s j}$ and Enppl $1^{a s j-2 J}$ mice serve as novel models recapitulating the mineralization phenotype seen in patients with GACI. In further studies, an $N t 5 e^{-1-}$ knockout mouse has been characterized as a model of ACDC. ${ }^{29}$ These mice demonstrated mineralization in the juxta-articular joint capsules but not in vascular tissues. These mouse models attest to the presence of complex promineralization/antimineralization networks that are required under physiological homeostatic conditions to prevent ectopic tissue mineralization.

The mouse models of PXE have been useful for detailed examination of pathomechanisms of ectopic mineralization in general, and they have provided a platform to develop novel treatment approaches. Mice, however, are too small to examine certain fundamental aspects of pathogenesis by experimental procedures, such as liver and kidney transplantation. Recently, a knockout rat model for PXE was developed by targeted inactivation of the Abcc 6 gene by zinc finger nuclease, for the purpose of providing a larger animal model for pathophysiological studies. ${ }^{9}$ This rat model has been shown to develop ectopic mineralization similar to PXE in mice and humans, and their plasma PPi levels are reduced to $<30 \%$ of the wild-type controls. Liver and kidney perfusion studies in this rat model suggested a critical role for hepatic ABCC6-dependent formation of PPi under physiological conditions, and ABCC6 expression in the liver has been identified as the main source of PPi in circulation. ${ }^{9}$
In addition to the rodent models for PXE, zebrafish have provided another system to study ectopic mineralization disorders. There are a total of four zebrafish mutants for the human $A B C C 6$ ortholog abcc6a in zebrafish that have been characterized, including a stable abcc6a knockout zebrafish. ${ }^{30}$ Although there are similarities in the axial skeleton hypermineralization phenotype in this and three other abcc $6 a$ zebrafish models, ${ }^{31-33}$ none of them develops ectopic mineralization in the skin, eyes, and vasculature in a similar pattern as seen in patients with PXE and $A b c c 6^{-1-}$ murine models of PXE.

\section{Identification of Antimineralization Compounds in Mouse Models of Ectopic Mineralization: Bisphosphonates}

The unifying pathogenic feature in mouse models for PXE, GACI, and ACDC is reduced plasma levels of PPi, and this has also been demonstrated in patients with PXE and $\mathrm{GACI}^{2,3}$ Because PPi is a strong antimineralization factor, whereas $\mathrm{Pi}$ promotes mineralization, a reduced $\mathrm{PPi} / \mathrm{Pi}$ ratio results in ectopic mineralization. A straightforward approach to counteract ectopic mineralization in these mice would be to normalize the PPi levels in plasma by direct PPi infusion. However, because of instability and the short halflife of PPi, stable PPi analogs, bisphosphonates, have been tested in the murine model systems of ectopic mineralization (Figure 3). ${ }^{34,35}$ Bisphosphonates have two major pharmacologic properties. ${ }^{36}$ On one hand, they prevent the ectopic mineralization, whereas on the other hand, they prevent osteoporosis by inhibiting osteoclast activity. The balance between the two effects is dependent on their chemical structure. The newer, nitrogen-containing bisphosphonates predominantly inhibit osteoclast activity, whereas the older, non-nitrogen-containing bisphosphonates prevent ectopic mineralization and are far less potent inhibitors of osteoclasts. The potential efficacy of bisphosphates to prevent ectopic mineralization was tested in the $A b c c 6^{-1-}$ mouse model for PXE. ${ }^{34}$ The treatment consisted of feeding the mice a diet containing etidronate or injecting the mice with etidronate subcutaneously. The mice were treated at 4 weeks of age with etidronate, before the mineralization process ensues, and the degree of mineralization in muzzle skin was assessed at 12 weeks by either semiquantitative histopathology or direct chemical assay of calcium. Etidronate treatment in $12 \times$ quantities of the human doses for treating osteoporosis resulted in a significant reduction in the amount of mineralization with concomitant changes in the bone microarchitecture in the $A b c c 6^{-1-}$ mice (Figure 3). Interestingly, the nitrogen-containing bisphosphonate, alendronate, did not show a therapeutic effect in the $A b c c 6^{-/-}$mice, which was attributed to its lower antimineralization potency. ${ }^{34}$

This study was accompanied by further characterization of the effects of bisphosphonates on ectopic mineralization 
A<smiles>O=P(O)(O)OP(=O)(O)OP(=O)(O)O</smiles>

B

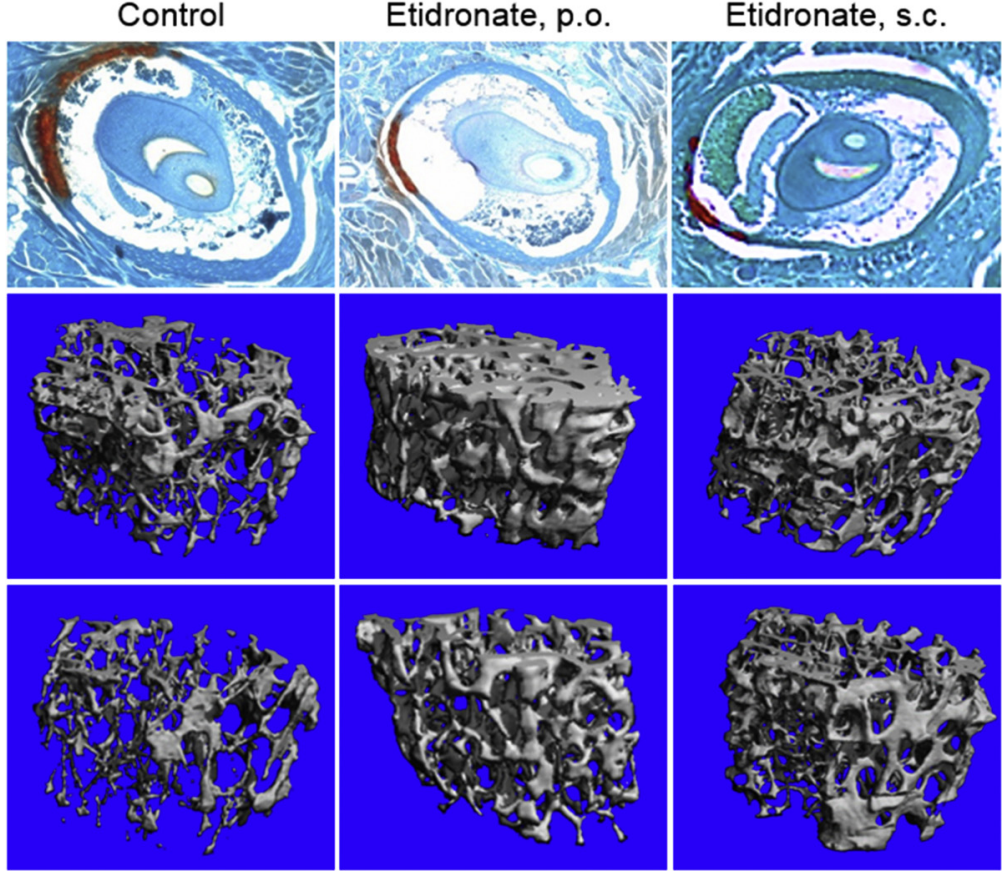

Etidronate<smiles>[R2]C([R2])(P(=O)(O)O)P(=O)(O)O</smiles><smiles>CC(O)(P(=O)(O)O)P(=O)(O)O</smiles>

Figure 3 Treatment of $\mathrm{AbccC}^{-/-}$mice, a model of pseudoxanthoma elasticum, with etidronate, a bisphosphonate analog of inorganic pyrophosphate (PPi), prevents ectopic mineralization. A: Bisphosphonates (BPs) are stable analogs of PPi because of the presence of a carbon bond, instead of oxygen, and the presence of side chains (R1 and R2). B: Top left panel: $A b c c 6^{-/-}$mice at 12 weeks of age demonstrate extensive mineralization of the connective sheath of vibrissae in the muzzle skin, as demonstrated by Alizarin Red stain. Administration of etidronate either orally (p.o.; top middle panel) or by s.c. injections (top right panel) during weeks 4 to 12 significantly reduced the mineral deposits. Administration of etidronate also significantly increased the density of trabecular bone both in male (middle row) and in female (bottom row) mice. Adapted with permission from Li et al. ${ }^{34}$ combined with analysis of the bone microarchitecture in the Enppl ${ }^{a s j}$ mouse model of GACI. ${ }^{35}$ Treatment with etidronate demonstrated dual beneficial effects in significantly reduced mineralization in the skin and aorta as well as corrected the hypomineralization of bone in Enppl ${ }^{a s j}$ mice. ${ }^{35}$ A novel approach for treatment of GACI in Enppl ${ }^{a s j}$ mice has been suggested by administration of recombinant human ENPP1 to compensate for the loss of the mouse endogenous ENPP1. This enzyme replacement therapy resulted in elevated plasma PPi levels, reduced the extent of ectopic mineralization, and prevented mortality. ${ }^{37}$

The clinical efficiency of etidronate to counteract ectopic mineralization was recently also determined in a cohort of PXE patients in the Treatment of Ectopic Mineralization in Pseudoxanthoma Elasticum Trial (TEMP). In this doubleblinded study, etidronate was found to inhibit arterial media calcification and to reduce the appearance of ocular complications. ${ }^{38}$ These were remarkable results, considering the slowly progressive nature of PXE and the relatively limited time (1 year) the patients were treated. Although the results of the TEMP Trial are encouraging, more work is needed to determine the efficacy and especially safety of etidronate in PXE patients.

\section{Dietary Magnesium as an Inhibitor of Ectopic Mineralization}

Another recently completed clinical trial attempted to test the effect of oral magnesium on progression and severity of PXE. This study was predicated on previous demonstrations in the $A b c c 6^{--}$mouse model of PXE that increase of the dietary magnesium, fivefold over the standard rodent diet, completely prevented the ectopic mineralization in these animals. ${ }^{39}$ Conversely, lowering of the magnesium content of the diet to $20 \%$ of the standard, together with a twofold increase in phosphorus content, significantly accelerated the ectopic mineralization. ${ }^{40}$ The patients were treated with diets supplemented with magnesium, $1.2 \mathrm{~g} / \mathrm{day}$, and the phenotypic changes were assessed by clinical examination, histopathology, and imaging studies. Although some improvement was noted in patients receiving magnesium supplementation, the results did not reach statistical significance, potentially implying that 1 -year follow-up over the natural history of PXE may not be long enough to document relatively small changes (M. Lebwohl, unpublished data). The adverse effects of magnesium supplementation include gastrointestinal disturbances, and it is unclear at this point 
whether magnesium supplementation plays a role as a potential treatment modality for PXE.

\section{Functionality of ABCC6 as a Putative Efflux Transporter}

The unifying pathogenic feature in mouse models for PXE and GACI is reduced plasma levels of PPi. Recent studies demonstrated ABCC6-dependent release of ATP, which is then converted to $\mathrm{PPi}$, an effective inhibitor of calcification. ${ }^{41,42}$ These studies used an in vitro model based on the functional reestablishment of polarity in freshly isolated (primary) hepatocyte cultures. In such cultures, the cell-cell contacts are retained in a similar manner as observed in liver tissue. It was shown that hepatocytes from wild-type mouse livers are able to release ATP over their sinusoidal membrane, followed by the appearance of PPi in medium of primary hepatocyte sandwich cultures, but significantly lower levels were detected in medium of hepatocytes lacking ABCC6. These results implied that hepatocytes release ATP in an ABCC6-dependent manner and are able to convert it to PPi. Similar observations were made when liver perfusates were analyzed in $A b c c 6^{-1-}$ mice and rats, ${ }^{9,42}$ indicating that hepatic ABCC6-mediated ATP release is the main source of circulating PPi, and loss of function of ABCC6 in PXE patients leads to plasma PPi deficiency with subsequent ectopic mineralization of connective tissues.

Although $\mathrm{ABC}$ proteins have been shown to transport cyclic nucleotides ${ }^{43-45}$ and nucleotide analogs, ${ }^{43,46}$ ATP is not among the currently known transported substrates. Cells are known to release ATP via exocytosis or through anion channels, such as pannexins, CalH1, and connexin hemichannels. The published data now support the role of ABCC6 in release of ATP from (liver) cells. ${ }^{9,41,42}$ The ABCC6-dependent conduit allows passage of nucleoside triphosphates in general, among which ATP is quantitatively the most important. ${ }^{41}$ This is a peculiar function for an $\mathrm{ABC}$ transporter: Most $\mathrm{ABC}$ proteins use the energy released by intracellular ATP hydrolysis to transport specific substrates across membranes, often against steep concentration gradients. ${ }^{47}$ What makes ABCC6-mediated cellular ATP release intriguing is that ATP might not need an active transport mechanism to leave cells because there is a huge concentration gradient for ATP across the plasma membrane, and a channel would suffice to get ATP out of the cell.

In patients with PXE and in mutant $A b c c 6$ mouse models, the PPi levels are approximately $30 \%$ of the controls, indicating the presence of other pathways independent of ABCC6 for release of ATP and generation of plasma PPi. ${ }^{48}$ In addition, the work by us and others suggests that PPi deficiency is the major, but not exclusive, cause of ectopic mineralization in PXE, and other as yet unknown mechanisms exist that are independent of PPi by which ABCC6 prevents ectopic mineralization under physiologic conditions. ${ }^{49,50}$ To this end, recent observations suggest that ABCC6 is also involved in extracellular nucleotide metabolism, suggesting a central role for ABCC6 in purinergic signaling in the development of ectopic mineralization. ${ }^{51,52}$

\section{Potential Mechanisms of ABCC6-Dependent Release of ATP from Hepatocytes}

It is presently unclear how ABCC6 mediates ATP release. One of the following mechanisms most likely accounts for the ATP release mediated by ABCC6: i) Similar to ABCC7, which encodes the cystic fibrosis transmembrane regulator, an ATP-gated chloride channel, ${ }^{53}$ ABCC6 might function as an ATP-dependent ATP channel. ii) ABCC6 could regulate an as yet unidentified ATP channel. Two examples within the $\mathrm{C}$ branch of the $\mathrm{ABC}$ superfamily that function via a similar mechanism are $\mathrm{ABCC} 8$ and $\mathrm{ABCC}$, both regulating the opening and closing of complex potassium channels. ${ }^{54}$ iii) ABCC6 might regulate exocytosis of ATP-loaded vesicles. ${ }^{55}$ iv) Most of the currently available data suggested that ABCC6 is simply an ATP-dependent efflux pump for ATP and other nucleotide triphosphates. Most members of the $\mathrm{C}$ subfamily of the ATP-biding cassette superfamily of membrane proteins, including the closest homolog of ABCC6, $\mathrm{ABCC} 1$, are bona fide organic anion efflux transporters, ${ }^{46,56}$ and ABCC6 has also been shown to transport a few organic anions, ${ }^{57,58}$ albeit sluggishly. ATP efflux rates found in HEK293-ABCC6 cells ${ }^{9}$ are compatible with direct transport because they are similar to the rates by which $\mathrm{ABCC} 1$ pumps morphine-3-glucuronide out of HEK293 cells. ${ }^{59}$ Intriguing differences in the nucleotide-binding properties between ABCC6 and ABCC1 also provide circumstantial evidence that ABCC6 transports ATP: Specifically, under conditions that support ATP hydrolysis (ie, the presence of substrate and temperature at $37^{\circ} \mathrm{C}$ ), the nucleotide-binding domains of $\mathrm{ABC}$ transporters, including $\mathrm{ABCC} 1$, can be labeled with the photoactive ATP analog 8-azido-ATP. Labeling depends on the presence of phosphate analogs, such as orthovanadate or beryllium fluoride, to trap 8-azido-ADP at the nucleotidebinding domains. However, ABCC6 is also labeled in the absence of phosphate analogs. ${ }^{60}$ Moreover, although phosphate analogs increase 8-azido-ATP labeling of ABCC6, unlike $\mathrm{ABCC} 1$, this does not require the addition of a specific substrate.$^{61}$ A plausible explanation for these results is that 8azido-ATP binds not only to the nucleotide-binding domains of ABCC6, but also to its substrate-binding/translocation site.

Providing experimental proof for direct ABCC6-mediated ATP transport has proved to be challenging because of technical difficulties in following ATP transport in vesicular uptake experiments, which are considered the gold standard to prove that a specific molecule is a substrate of an $\mathrm{ABC}$ transporter. A major problem with following ATP transport in the vesicular uptake experiments is the fact that high concentrations (mmol/L range) of ATP are needed to drive transport by $\mathrm{ABC}$ proteins. Only a fraction of the added ATP will be transported into the vesicles under these conditions, 
resulting in an unfavorable signal/noise ratio. The vesicles used in vesicular transport experiments are generated from cells overproducing ABCC6. ${ }^{41}$ These cells also express other channels that allow passage of ATP and contribute to the high background signal in vesicular uptake experiments. ${ }^{55,62} \mathrm{~A}$ solution for these problems might be the use of proteoliposomes with purified ABCC6, which will result in a more favorable signal/noise ratio. Despite the technical challenges, we expect that the mechanistic details of ABCC6-mediated cellular ATP release will soon be uncovered.

\section{Demonstration of Elevated Plasma PPi Levels in PXE Mice and in Human Volunteers after Oral Administration of PPi}

Reduced plasma PPi levels in PXE could be corrected by direct i.v. administration of PPi, but considering the possibility that the patients need to be continuously treated for prevention of the mineralization process, oral administration of PPi would be preferred. This approach has not been tested previously, presumably because it was assumed, on the basis of statements in the older literature, that PPi does not get absorbed from the gut. ${ }^{63}$ This assumption has been recently challenged by preliminary studies obtained in mice. The results of these studies demonstrated attenuation of ectopic mineralization in $A b c c 6^{-1-}$ mice as a result of oral PPi administration. ${ }^{64}$

In subsequent studies, 10 healthy human volunteers ingested a bolus of tetrasodium pyrophosphate solution; six individuals served as controls, drinking water only. Elevated plasma PPi levels in each individual were noted 30 and 60 minutes after ingestion of the PPi solution. ${ }^{64}$ These studies attest to the fact that PPi can be absorbed from the gut after oral ingestion, associated with increased plasma PPi levels. However, some caution is warranted before advocating oral PPi as a treatment for PXE patients. The human data obtained so far show that a large dose is needed to achieve a relatively modest increase in plasma PPi concentration, ${ }^{64}$ with the major part of ingested PPi being converted into inorganic $\mathrm{Pi}$, a potent promineralization factor. More important, our studies have shown that a diet with high amounts of Pi accelerates ectopic mineralization in $A b c c 6^{-/-}$rats and mice. ${ }^{9,65}$ More work is, therefore, needed to determine at which dose oral PPi might have beneficial effects on soft tissue mineralization.

Collectively, these preliminary studies support the hypothesis that restoration of plasma PPi levels can be elicited by different mechanisms, including enhanced release of ATP from cells in an ABCC6-independent manner and by direct administration of PPi to the animal models and patients with PXE.

\section{Outstanding Issues and Experimental Challenges}

Although much progress has been made in the past decade related to the understanding of the pathomechanisms of
PXE, developing effective therapies for systematic manifestations of PXE continues to be a challenge. One of the issues relates to the intrafamilial and interfamilial heterogeneity in PXE in families with the same mutations in the same gene. The most striking example of such phenotypic severity is the demonstration that some patients diagnosed as having GACI with extremely severe vascular calcification at the early postnatal period have ABCC6 mutations, whereas precisely the same mutation has been identified in families with slowly progressing late-onset manifestations of classic PXE ${ }^{15}$ One plausible explanation is the presence of modifier genes that act on the phenotype predicated on biallelic ABCC6 mutations. ${ }^{3}$ Furthermore, extensive mouse studies have identified genomic regions that may harbor modifier genes, as noted by the extensive variability in the degree of ectopic mineralization as a result of the same Abcc6 single-nucleotide polymorphism in different strains of mice. ${ }^{3}$ Collectively, the ectopic mineralization phenotype in PXE is highly variable, reflecting the types and combinations of mutations in different genes, juxtaposed into the environmental factors and lifetime variables at the environment-genome interface.

Although some progress has been made in the development of potential treatment modalities for PXE, to the extent that some of them have entered early clinical trials, these approaches seem to be able to prevent development of mineral deposits; however, none of these therapies has proved efficacious in removing extensive pathologic mineralization. This notion is particularly important because the patients at the time of diagnosis have already extensive ectopic mineralization with accompanying clinical findings. In this regard, ${ }^{3}$ experimental treatments for patients with GACI consist of feeding the pregnant mother with etidronate, followed by treatment of the newborn affected individual with a combination of bisphosphonate and sodium thiosulfate, a US Food and Drug Administration-approved agent, with the ability to increase the solubility of calcium as used for the treatment of calciphylaxis.

Another approach to potentially reverse the existing tissue mineralization will take advantage of the ability of EDTA to chelate calcium in a targeted microenvironment. Specifically, the mineral deposits in PXE reside in elastic connective tissues in the skin, in the Bruch membrane of the retina, and in media of the arterial blood vessels. As a consequence, there is evidence that mineralization of these structures leads to elastorrhexis (ie, fragmentation of the elastic structures), exposing their elastin core. Thus, targeting EDTA to the sites of aberrant mineralization can be achieved by delivery in albumin nanoparticles, conjugated with antielastin antibodies. This concept has recently been used in in vitro and ex vivo studies and was shown to result in release of the calcium ions from arterial tissue. ${ }^{66-68}$ Consequently, in addition to preventing further mineralization by approaches such as etidronate, reversal of the calcium deposits is of utmost importance to alleviate the clinical findings that led to the original diagnosis of PXE. 
The latter observations emphasize that there are several issues that are critical for successful development of clinical trials for PXE. First, there is no reliable serum biomarker that would allow accurate monitoring of the disease activity as a result of drug treatment. Furthermore, the natural history of PXE is protean, and even a 1-year follow-up may not be sufficient to capture net changes in the phenotype that may accompany the therapy. Finally, recent rodent studies with mouse and rat models of PXE have suggested that in addition to the pathway involving alterations in the plasma level of PPi, additional mechanisms complementary to this pathway may exist. ${ }^{49-51}$

In summary, PXE is a complex ectopic mineralization disorder. With the advent of enhanced understanding of the pathomechanisms of ectopic mineralization as a result of mutations in $A B C C 6$, several potential approaches are currently being tested toward development of treatment modalities for this currently intractable disorder. Some of these treatment approaches have already reached the early clinical trial levels, and it is conceivable that novel efficient treatments may become available soon.

\section{Acknowledgments}

This Mini-Review is dedicated to the honor of Professor Andras Váradi on his 70th birthday.

We thank Carol Kelly for assistance in manuscript preparation.

\section{Supplemental Data}

Supplemental material for this article can be found at https://doi.org/10.1016/j.ajpath.2018.09.014.

\section{References}

1. Budoff MJ, Shaw LJ, Liu ST, Weinstein SR, Mosler TP, Tseng PH, Flores FR, Callister TQ, Raggi P, Berman DS: Long-term prognosis associated with coronary calcification: observations from a registry of 25,253 patients. J Am Coll Cardiol 2007, 49:1860-1870

2. Li Q, Uitto J: Mineralization/anti-mineralization networks in the skin and vascular connective tissues. Am J Pathol 2013, 183:10-18

3. Uitto J, Li Q, van de Wetering K, Varadi A, Terry SF: Insights into pathomechanisms and treatment development in heritable ectopic mineralization disorders: summary of the PXE International Biennial Research Symposium-2016. J Invest Dermatol 2017, 137:790-795

4. Neldner KH: Pseudoxanthoma elasticum. Clin Dermatol 1988, 6: $1-159$

5. Christiano AM, Lebwohl MG, Boyd CD, Uitto J: Workshop on pseudoxanthoma elasticum: molecular biology and pathology of the elastic fibers: Jefferson Medical College, Philadelphia, Pennsylvania, June 10, 1992. J Invest Dermatol 1992, 99:660-663

6. Raybould MC, Birley AJ, Moss C, Hulten M, McKeown CM: Exclusion of an elastin gene (ELN) mutation as the cause of pseudoxanthoma elasticum (PXE) in one family. Clin Genet 1994, 45: $48-51$

7. Belinsky MG, Kruh GD: MOAT-E (ARA) is a full-length MRP/cMOAT subfamily transporter expressed in kidney and liver. Br J Cancer 1999, 80:1342-1349
8. Jiang Q, Endo M, Dibra F, Wang K, Uitto J: Pseudoxanthoma elasticum is a metabolic disease. J Invest Dermatol 2009, 129:348-354

9. Li Q, Kingman J, van de Wetering K, Tannouri S, Sundberg JP, Uitto J: Abcc6 knockout rat model highlights the role of liver in PPi homeostasis in pseudoxanthoma elasticum. J Invest Dermatol 2017, 137:1025-1032

10. Pfendner EG, Vanakker OM, Terry SF, Vourthis S, McAndrew PE, McClain MR, Fratta S, Marais AS, Hariri S, Coucke PJ, Ramsay M, Viljoen D, Terry PF, De Paepe A, Uitto J, Bercovitch LG: Mutation detection in the ABCC6 gene and genotype-phenotype analysis in a large international case series affected by pseudoxanthoma elasticum. J Med Genet 2007, 44:621-628

11. Nitschke Y, Baujat G, Botschen U, Wittkampf T, du Moulin M, Stella J, Le Merrer M, Guest G, Lambot K, Tazarourte-Pinturier MF, Chassaing N, Roche O, Feenstra I, Loechner K, Deshpande C, Garber SJ, Chikarmane R, Steinmann B, Shahinyan T, Martorell L, Davies J, Smith WE, Kahler SG, McCulloch M, Wraige E, Loidi L, Hohne W, Martin L, Hadj-Rabia S, Terkeltaub R, Rutsch F: Generalized arterial calcification of infancy and pseudoxanthoma elasticum can be caused by mutations in either ENPP1 or ABCC6. Am J Hum Genet 2012, 90:25-39

12. Rutsch F, Boyer P, Nitschke Y, Ruf N, Lorenz-Depierieux B, Wittkampf T, Weissen-Plenz G, Fischer RJ, Mughal Z, Gregory JW, Davies JH, Loirat C, Strom TM, Schnabel D, Nurnberg P, Terkeltaub R: Hypophosphatemia, hyperphosphaturia, and bisphosphonate treatment are associated with survival beyond infancy in generalized arterial calcification of infancy. Circ Cardiovasc Genet 2008, 1:133-140

13. St Hilaire C, Ziegler SG, Markello TC, Brusco A, Groden C, Gill F, Carlson-Donohoe H, Lederman RJ, Chen MY, Yang D, Siegenthaler MP, Arduino C, Mancini C, Freudenthal B, Stanescu HC, Zdebik AA, Chaganti RK, Nussbaum RL, Kleta R, Gahl WA, Boehm M: NT5E mutations and arterial calcifications. N Engl J Med 2011, 364:432-442

14. Markello TC, Pak LK, St Hilaire C, Dorward H, Ziegler SG, Chen MY, Chaganti K, Nussbaum RL, Boehm M, Gahl WA: Vascular pathology of medial arterial calcifications in NT5E deficiency: implications for the role of adenosine in pseudoxanthoma elasticum. Mol Genet Metab 2011, 103:44-50

15. Li Q, Brodsky JL, Conlin L, Pawel B, Glatz A, Gafni RI, Schurgers LJ, Uitto J, Hakonarson H, Deardoff MA, Levine M: Mutations in the ABCC6 gene as a cause of generalized arterial calcification of infancy: genotypic overlap with pseudoxanthoma elasticum. J Invest Dermatol 2014, 134:658-665

16. Vanakker OM, Martin L, Gheduzzi D, Leroy BP, Loeys BL, Guerci VI, Matthys D, Terry SF, Coucke PJ, Pasquali-Ronchetti I, De Paepe A: Pseudoxanthoma elasticum-like phenotype with cutis laxa and multiple coagulation factor deficiency represents a separate genetic entity. J Invest Dermatol 2007, 127:581-587

17. Li Q, Schurgers LJ, Smith AC, Tsokos M, Uitto J, Cowen EW: Coexistent pseudoxanthoma elasticum and vitamin K-dependent coagulation factor deficiency: compound heterozygosity for mutations in the GGCX gene. Am J Pathol 2009, 174:534-540

18. Li Q, Grange DK, Armstrong NL, Whelan AJ, Hurley MY, Rishavy MA, Hallgren KW, Berkner KL, Schurgers LJ, Jiang Q, Uitto J: Mutations in the GGCX and ABCC6 genes in a family with pseudoxanthoma elasticum-like phenotypes. J Invest Dermatol 2009, 129:553-563

19. Farrow EG, Imel EA, White KE: Miscellaneous non-inflammatory musculoskeletal conditions: hyperphosphatemic familial tumoral calcinosis (FGF23, GALNT3 and alphaKlotho). Best Pract Res Clin Rheumatol 2011, 25:735-747

20. Topaz O, Indelman M, Chefetz I, Geiger D, Metzker A, Altschuler Y, Choder M, Bercovich D, Uitto J, Bergman R, Richard G, Sprecher E: A deleterious mutation in SAMD9 causes normophosphatemic familial tumoral calcinosis. Am J Hum Genet 2006, 79:759-764 
21. Sprecher E: Familial tumoral calcinosis: from characterization of a rare phenotype to the pathogenesis of ectopic calcification. J Invest Dermatol 2010, 130:652-660

22. Klement JF, Matsuzaki Y, Jiang QJ, Terlizzi J, Choi HY, Fujimoto N, Li K, Pulkkinen L, Birk DE, Sundberg JP, Uitto J: Targeted ablation of the Abcc6 gene results in ectopic mineralization of connective tissues. Mol Cell Biol 2005, 25:8299-8310

23. Gorgels TG, Hu X, Scheffer GL, van der Wal AC, Toonstra J, de Jong PT, van Kuppevelt TH, Levelt CN, de Wolf A, Loves WJ, Scheper RJ, Peek R, Bergen AA: Disruption of Abcc6 in the mouse: novel insight in the pathogenesis of pseudoxanthoma elasticum. Hum Mol Genet 2005, 14:1763-1773

24. Berndt A, Li Q, Potter CS, Liang Y, Silva KA, Kennedy V, Uitto J, Sundberg JP: A single-nucleotide polymorphism in the Abcc6 gene associates with connective tissue mineralization in mice similar to targeted models for pseudoxanthoma elasticum. J Invest Dermatol 2013, 133:833-836

25. Li Q, Berndt A, Guo H, Sundberg J, Uitto J: A novel animal model for pseudoxanthoma elasticum: the KK/HIJ mouse. Am J Pathol 2012, 181:1190-1196

26. Li Q, Guo H, Chou DW, Berndt A, Sundberg JP, Uitto J: Mouse models for pseudoxanthoma elasticum: genetic and dietary modulation of the ectopic mineralization phenotypes. PLoS One 2013, 9: e89268

27. Li Q, Guo H, Chou DW, Berndt A, Sundberg JP, Uitto J: Mutant Enpp $1^{\text {asj }}$ mouse as a model for generalized arterial calcification of infancy. Dis Model Mech 2013, 6:1227-1235

28. Li Q, Pratt CH, Dionne LA, Fairfield H, Karst SY, Sundberg JP, Uitto J: Spontaneous asj-2J mutant mouse as a model for generalized arterial calcification of infancy: a large deletion/insertion mutation in the Enpp1 gene. PLoS One 2014, 9:e113542

29. Li Q, Price TP, Sundberg JP, Uitto J: Juxta-articular joint-capsule mineralization in CD73 deficient mice: similarities to patients with NT5E mutations. Cell Cycle 2014, 13:2609-2615

30. van Gils M, Willaert A, De Vilder E, Coucke P, Vanakker O: Generation and validation of the first complete knockout model of abcc6a in zebrafish. J Invest Dermatol 2018, 138:2333-2342

31. Li Q, Sadowski S, Frank M, Chai C, Varadi A, Ho SY, Lou H, Dean M, Thisse C, Thisse B, Uitto J: The abcc6a gene expression is required for normal zebrafish development. J Invest Dermatol 2010, 130:2561-2568

32. Busch-Nentwich E, Kettleborough R, Harvey S, Collins J, Ding M, Dooley C, Fenyes F, Gibbons R, Herd C, Mehroke S, Scahill C, Sealy I, Wali N, White R, Stemple DL: Sanger Institute Zebrafish Mutation Project Mutant, Phenotype and Image Data Submission. ZFIN Direct Data, 2012, ZDB-PUB-120207-1

33. Mackay EW, Apschner A, Schulte-Merker S: Vitamin K reduces hypermineralisation in zebrafish models of PXE and GACI. Development 2015, 142:1095-1101

34. Li Q, Sundberg JP, Levine MA, Terry SF, Uitto J: The effects of bisphosphonates on ectopic soft tissue mineralization caused by mutations in the ABCC6 gene. Cell Cycle 2015, 14: 1082-1089

35. Li Q, Kingman J, Sundberg JP, Levine MA, Uitto J: Dual effects of bisphosphonates on ectopic skin and vascular soft tissue mineralization versus bone microarchitecture in a mouse model of generalized arterial calcification of infancy. J Invest Dermatol 2016, 136: $275-283$

36. Russell RG: Bisphosphonates: from bench to bedside. Ann N Y Acad Sci 2006, 1068:367-401

37. Albright RA, Stabach P, Cao W, Kavanagh D, Mullen I, Braddock AA, Covo MS, Tehan M, Yang G, Cheng Z, Bouchard K, Yu ZX, Thorn S, Wang X, Folta-Stogniew EJ, Negrete A, Sinusas AJ, Shiloach J, Zubal G, Madri JA, De La Cruz EM, Braddock DT: ENPP1-Fc prevents mortality and vascular calcifications in rodent model of generalized arterial calcification of infancy. Nat Commun 2015, 6:10006
38. Kranenburg G, de Jong PA, Bartstra JW, Lagerweij SJ, Lam MG, Ossewaarde-van Norel J, Risseeuw S, van Leeuwen R, Imhof SM, Verhaar HJ, de Vries JJ, Slart RHJA, Luurtsema G, den Harder AM, Visseren FLJ, Mali WP, Spiering W: Etidronate for prevention of ectopic mineralization in patients with pseudoxanthoma elasticum. J Am Coll Cardiol 2018, 71:1117-1126

39. LaRusso J, Li Q, Jiang Q, Uitto J: Elevated dietary magnesium prevents connective tissue mineralization in a mouse model of pseudoxanthoma elasticum $\left(\right.$ Abcc6 $^{-/-}$). J Invest Dermatol 2009, 129: $1388-1394$

40. Jiang Q, Uitto J: Restricting dietary magnesium accelerates ectopic connective tissue mineralization in a mouse model of pseudoxanthoma elasticum $\left(\mathrm{Abcc6}^{-1-}\right)$. Exp Dermatol 2012, 21: 694-699

41. Jansen RS, Kucukosmanoglu A, de Haas M, Sapthu S, Otero JA, Hegman IE, Bergen AA, Gorgels TG, Borst P, van de Wetering K: ABCC6 prevents ectopic mineralization seen in pseudoxanthoma elasticum by inducing cellular nucleotide release. Proc Natl Acad Sci U S A 2013, 110:20206-20211

42. Jansen RS, Duijst S, Mahakena S, Sommer D, Szeri F, Varadi A, Plomp A, Bergen AA, Oude Elferink RP, Borst P, van de Wetering K: ABCC6-mediated ATP secretion by the liver is the main source of the mineralization inhibitor inorganic pyrophosphate in the systemic circulation-brief report. Arterioscler Thromb Vasc Biol 2014, 34:1985-1989

43. Reid G, Wielinga P, Zelcer N, De Haas M, Van Deemter L, Wijnholds J, Balzarini J, Borst P: Characterization of the transport of nucleoside analog drugs by the human multidrug resistance proteins MRP4 and MRP5. Mol Pharmacol 2003, 63:1094-1103

44. Wielinga PR, van der Heijden I, Reid G, Beijnen JH, Wijnholds J, Borst P: Characterization of the MRP4- and MRP5-mediated transport of cyclic nucleotides from intact cells. J Biol Chem 2003, 278 : $17664-17671$

45. de Wolf CJ, Yamaguchi H, van der Heijden I, Wielinga PR, Hundscheid SL, Ono N, Scheffer GL, de Haas M, Schuetz JD, Wijnholds J, Borst P: cGMP transport by vesicles from human and mouse erythrocytes. FEBS J 2007, 274:439-450

46. Borst $\mathrm{P}$, de Wolf $\mathrm{C}$, van de Wetering $\mathrm{K}$ : Multidrug resistanceassociated proteins 3, 4, and 5. Pflugers Arch 2007, 453:661-673

47. Borst $\mathrm{P}$, Elferink RO: Mammalian $\mathrm{ABC}$ transporters in health and disease. Annu Rev Biochem 2002, 71:537-592

48. Lohman AW, Billaud M, Isakson BE: Mechanisms of ATP release and signalling in the blood vessel wall. Cardiovasc Res 2012, 95: 269-280

49. Pomozi V, Brampton C, van de Wetering K, Zoll J, Calio B, Pham K, Owens JB, Marh J, Moisyadi S, Varadi A, Martin L, Bauer C, Erdmann J, Aherrahrou Z, Le Saux O: Pyrophosphate supplementation prevents chronic and acute calcification in ABCC6-deficient mice. Am J Pathol 2017, 187:1258-1272

50. Zhao J, Kingman J, Sundberg JP, Uitto J, Li Q: Plasma PPi deficiency is the major, but not the exclusive, cause of ectopic mineralization in an Abcc6(-/-) mouse model of PXE. J Invest Dermatol 2017, 137: $2336-2343$

51. Kauffenstein G, Yegutkin GG, Khiati S, Pomozi V, Le Saux O, Leftheriotis G, Lenaers G, Henrion D, Martin L: Alteration of extracellular nucleotide metabolism in pseudoxanthoma elasticum. J Invest Dermatol 2018, 138:1862-1870

52. Ziegler SG, Ferreira CR, MacFarlane EG, Riddle RC, Tomlinson RE, Chew EY, Martin L, Ma CT, Sergienko E, Pinkerton AB, Millan JL, Gahl WA, Dietz HC: Ectopic calcification in pseudoxanthoma elasticum responds to inhibition of tissue-nonspecific alkaline phosphatase. Sci Trans1 Med 2017, 9:eaal1669

53. Liu F, Zhang Z, Csanady L, Gadsby DC, Chen J: Molecular structure of the human CFTR ion channel. Cell 2017, 169:85-95.e8

54. Bryan J, Munoz A, Zhang X, Dufer M, Drews G, Krippeit-Drews P, Aguilar-Bryan L: $\mathrm{ABCC} 8$ and $\mathrm{ABCC} 9$ : $\mathrm{ABC}$ transporters that regulate $\mathrm{K}+$ channels. Pflugers Arch 2007, 453:703-718 
55. Lazarowski ER: Vesicular and conductive mechanisms of nucleotide release. Purinergic Signal 2012, 8:359-373

56. Borst P, Evers R, Kool M, Wijnholds J: The multidrug resistance protein family. Biochim Biophys Acta 1999, 1461:347-357

57. Belinsky MG, Chen ZS, Shchaveleva I, Zeng H, Kruh GD: Characterization of the drug resistance and transport properties of multidrug resistance protein 6 (MRP6, ABCC6). Cancer Res 2002, 62: $6172-6177$

58. Ilias A, Urban Z, Seidl TL, Le Saux O, Sinko E, Boyd CD, Sarkadi B, Varadi A: Loss of ATP-dependent transport activity in pseudoxanthoma elasticum-associated mutants of human ABCC6 (MRP6). J Biol Chem 2002, 277:16860-16867

59. van de Wetering K, Zelcer N, Kuil A, Feddema W, Hillebrand M, Vlaming ML, Schinkel AH, Beijnen JH, Borst P: Multidrug resistance proteins 2 and 3 provide alternative routes for hepatic excretion of morphine-glucuronides. Mol Pharmacol 2007, 72:387-394

60. Cai J, Daoud R, Alqawi O, Georges E, Pelletier J, Gros P: Nucleotide binding and nucleotide hydrolysis properties of the $\mathrm{ABC}$ transporter MRP6 (ABCC6). Biochemistry 2002, 41:8058-8067

61. Cai J, Daoud R, Georges E, Gros P: Functional expression of multidrug resistance protein 1 in Pichia pastoris. Biochemistry 2001, 40:8307-8316
62. Clairmont CA, De Maio A, Hirschberg CB: Translocation of ATP into the lumen of rough endoplasmic reticulum-derived vesicles and its binding to luminal proteins including $\mathrm{BiP}$ (GRP 78) and GRP 94. J Biol Chem 1992, 267:3983-3990

63. Orriss IR, Arnett TR, Russell RG: Pyrophosphate: a key inhibitor of mineralisation. Curr Opin Pharmacol 2016, 28:57-68

64. Dedinszki D, Szeri F, Kozak E, Pomozi V, Tokesi N, Mezei TR, Merczel K, Letavernier E, Tang E, Le Saux O, Aranyi T, van de Wetering K, Varadi A: Oral administration of pyrophosphate inhibits connective tissue calcification. EMBO Mol Med 2017, 9:1463-1470

65. Li Q, Uitto J: The mineralization phenotype in $\mathrm{Abcc6}^{-/-}$mice is affected by Ggcx gene deficiency and genetic background: a model for pseudoxanthoma elasticum. J Mol Med (Berl) 2010, 88:173-181

66. Lei Y, Nosoudi N, Vyavahare N: Targeted chelation therapy with EDTA-loaded albumin nanoparticles regresses arterial calcification without causing systemic side effects. J Control Release 2014, 196: 79-86

67. Lei Y, Grover A, Sinha A, Vyavahare N: Efficacy of reversal of aortic calcification by chelating agents. Calcif Tissue Int 2013, 93:426-435

68. Sinha A, Shaporev A, Nosoudi N, Lei Y, Vertegel A, Lessner S, Vyavahare N: Nanoparticle targeting to diseased vasculature for imaging and therapy. Nanomedicine 2014, 10:1003-1012 